\title{
PETROLOGIA E GEOQUÍMICA DOS STOCKS GRANITICOS DE SERRITA, PERNAMBUCO
}

\author{
SÉRGIO P. NEVES*
}

\begin{abstract}
Systematic geologic mapping of three granitic stocks intrusive in intermediate-grade metasediments of the Salgueiro Group, next to Serrita, Pernambuco, revealed ring-structures in two of them. Epidote-bearing and biotite-granodiorites predominate in the cores of the stocks but the rims, usually in topographic relief, are composed of aegirine-granites. Normative compositions of the biotite-granodiorites lie in or next to the Barker's trondhjemitic field in the Ab-An-Or diagram, whereas the aegirine-granites lie in the granite field. The biotite-granodiorites are meta to peraluminous (agpaitic index between 0.67 to 0.93 ) and the aegirine granites show peralkaline tendency (agpaitic index from 0.93 to 1.02 ). The high $\mathrm{Ba}$ and $\mathrm{Sr}$ values in the rock groups are common to cummulate rocks and the trace elements are comparable ( $\mathrm{Nb}, \mathrm{Zr}, \mathrm{Y}$ and $\Sigma \mathrm{REE}$ somewhat higher in the granites). $\mathrm{REE}$ patterns are characterized by high $\mathrm{Ce} / \mathrm{Yb}$ values, discrete positive $\mathrm{Eu}$ anomaly and by an extreme improverishment of HREE in the biotite granodiorites and lack of Eu anomaly in the aegirine-granites. $\delta 18 \mathrm{O}$ values increase towards the core of the stocks, generating an elongate pattern in the $\mathrm{SE}-\mathrm{NE}$ direction. A generation through partial fusion of garnet-amphibolite source and subsequent crystallization at pressures between 6 and $8 \mathrm{kbar}$ for the granodiorites is compatible with the present data, whereas the granites may have resulted from the crystallization of a residual granodioritic liquid at lower pressures or from the remelting of the granodiorites caused by a rapid uplift.
\end{abstract}

INTRODUÇÃo Três stocks graníticos ocorrem próximos à cidade de Serrita, Pernambuco, cerca de $550 \mathrm{~km}$ a oeste do Recife (Fig. 1). Os dois maiores têm formas circulares, com diâmetros aproximados de $10 \mathrm{~km}$ (Stock de Serrita) e $7 \mathrm{~km}$ (stock a sudoeste de Serrita). O menor é alongado na direção NE-SW e tem eixo maior de $3,5 \mathrm{~km}$ e menor de $2 \mathrm{~km}$. A porção central dos stocks é topograficamente arrasada enquanto os bordos podem constituir relevos destacados, entre estes destacando-se as serras de Serrita, no Stock de Serrita, e as da Vassoura, dos Macacos e do Boqueirão, no stock a sudoeste de Serrita.

Os stocks são intrusivos em rochas metassedimentares proterozóicas do Grupo Salgueiro (Barbosa 1970), nas quais predominam biotita xistos, que gradam a clorita xistos, em que têm sido reconhecidas três fases do dobramento (Sial et al. 1983).

Até o presente, trabalhos detalhados sobre as rochas destes corpos não foram realizados. Caldasso (1967a, 1967b), durante o mapeamento geológico das quadrículas E-093 e E-094, denominou-as descritivamente granitos róseos em oposição aos granitos cinza que ocorrem ao norte de Serrita intrudindo metassedimentos de baixo grau do Grupo Cachoeirinha (Barbosa 1970) e que foram designados por Almeida et al. (1967) de granitos tipo Conceição. No Projeto Cachoeirinha (Silva Filho 1985), elaborado pela Companhia de Pesquisas de Recursos Minerais (CPRM) para o Departamento Nacional de Produção Mineral (DNPM), essas rochas aparecem como granodiorito e apenas uma breve descrição petrográfica é fornecida. Sial et al. (1981a, 1981b) discutiram brevemente a petrologia e a geoquímica de elementos maiores, quando reconheceram uma tendência trondhjemítica para as rochas da porção central dos stocks e deixado implícito o caráter peralcalino da Serra dos Macacos, onde foi reportada a presença de egirina. Quatro amostras de rocha total foram analisadas por Sial (1984a) para elementos terras-raras, que forneceram padrões semelhantes aos de tonalitos e trondhjemitos.
Durante o ano de 1985, mapeamentos geológicos na escala 1:25.000 foram conduzidos na área de exposição dos stocks e permitiu um detalhamento de sua estrutura. Os resultados desse trabalho, juntamente com 20 novas análises químicas de elementos maiores e traços e seis de elementos terras-raras, são aqui apresentados. Dados de padrões de distribuição de isótopos de oxigênio, cujas médias $(9,23$ e 9,43 para os stocks de Serrita e a SW de Serrita, respectivamente) foram apresentadas por Sial (1984b), são também discutidas e analisadas.

DESCRIÇÃO DO MAPA GEOLÓGICO A observação do mapa geológico (Fig. 1) evidencia uma estrutura anelar para os stocks maiores (no corpo menor não foram detectadas variações entre os bordos e o núcleo), a qual é mais bem desenvolvida no stock SW de Serrita, cujo bordo oeste e parte do bordo este estão em relevo e em cuja porção central uma elevação em forma de meia-lua sugere o desenvolvimento de um anel interno. No Stock de Serrita, pequenas elevações próximas a seu limite sul seguem o contorno do corpo e seu bordo norte, apesar de não estar em relevo ou formar apenas pequenos morros isolados, é constituído por rochas de composição distinta das da porção central.

Os contatos com as encaixantes são bruscos, muitas vezes marcados por falhas. Falhas transversais aos contatos em alguns locais provocam pequenos rejeitos. As encaixantes são dominantemente biotita xistos granatíferos que gradam a clorita xistos para oeste. Próximo aos contatos, sills graníticos gnaissificados, cuja foliação concorda com a xistosidade dos biotita xisto, possivelmente representam injeções de material dos stocks nas encaixantes. O corpo SW de Serrita intrude ainda, em sua porção oèste, um granodiorito cinza orientado, granulação de média a grossa, com fenocristais de plagioclásio e que localmente assume um aspecto migmatítico devido à injeção de numerosos veios félsicos. Outro corpo de composição similar a este ocorre no extremo sudoeste da área mapeada. Xenólitos das encai- 


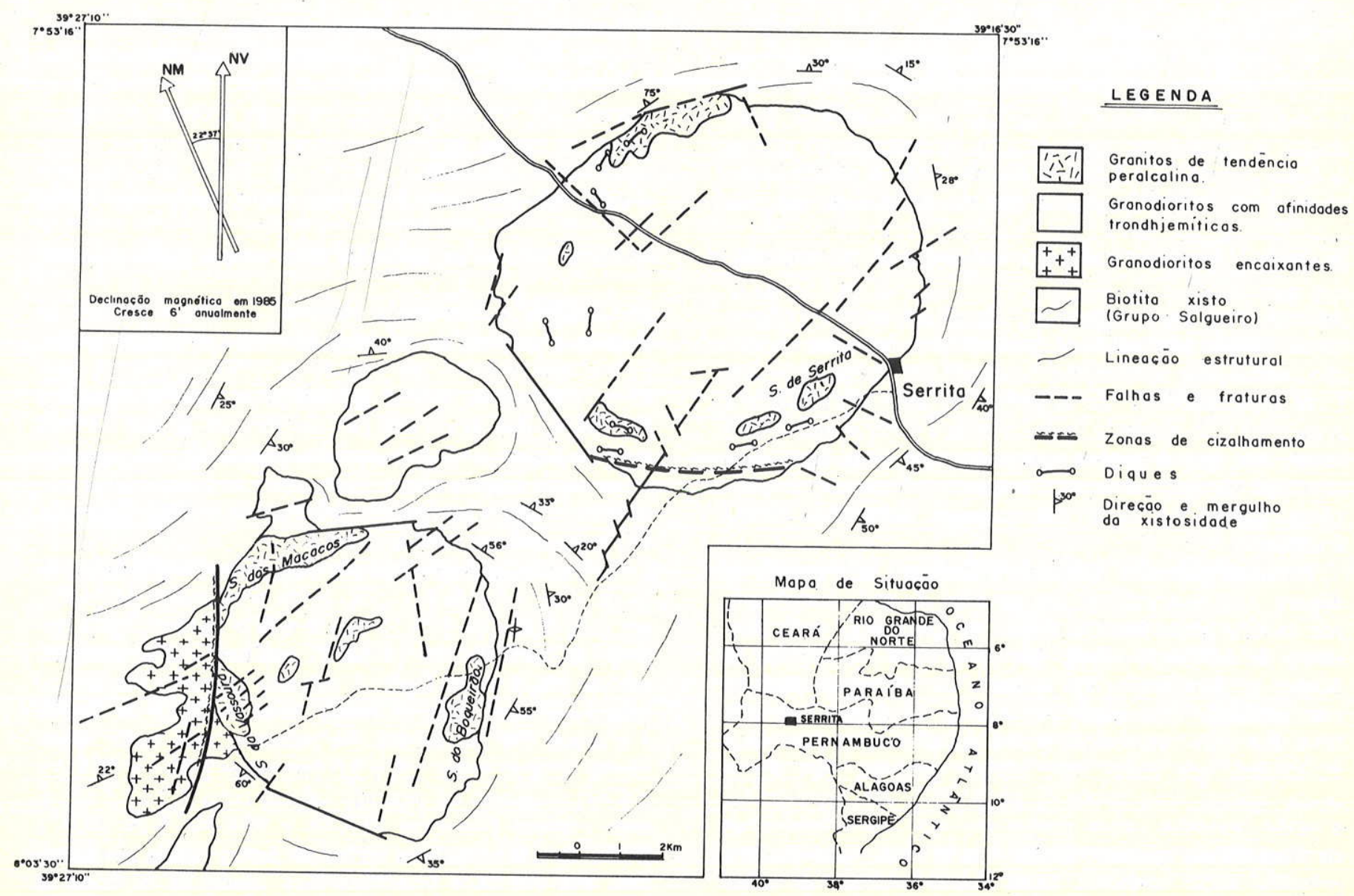

Figura 1 - Esboço geológico dos stocks graniticos de serrita (PE)

xantes não foram observados, embora Sial (1984b) refira sua ocorrência como hornfels na Serra dos Macacos.

Próximo ao contato com as encaixantes, uma orientação preferencial dada pelo paralelismo de cristais de plagioclásio está presente e chega a haver o desenvolvimento de uma foliação concordante com a dos xistos encaixantes no bordo este do Stock de Serrita. Esta orientação preferencial, porém, é bem menos desenvolvida ou está ausente no interior.

Diques com espessuras variando de poucos decímetros até $1 \mathrm{~m}$, geralmente colocados próximo ao bordo dos stocks, têm uma disposição espacial tendendo a contornar os mesmos.

Falhas e fraturas são bastante comuns. As principais direções de falhamento/fraturamento são NE-SW, E-W e N-S. As duas primeiras constituem pares de cisalhamento e são deslocados pela última, o que provoca o desenvolvimento de estruturas en échelon. Fraturamentos de direção NW-SE são subordinados e possivelmente representam o par conjugado daquelas de direção N-S. Pseudotaquilitos causados pelos falhamentos de direção NE-SW, E-W e $\mathrm{N}-\mathrm{S}$ são comuns. Falhamentos de direção $\mathrm{N}-\mathrm{S}$ e E-W podem ainda provocar zonas de cisalhamento com mais de $100 \mathrm{~m}$ de espessura.

PETROgRAFIA A porção central dos stocks é constituída de biotita granodioritos leucocráticos de granulação média e composição bastante uniforme. Quartzo, plagioclá- sio (albita/oligoclásio) e microclina perfazem mais de $90 \%$ da rocha e comumente mais de $95 \%$; biotita e, localmente, anfibólio ocorrem em quantidades subordinadas; como acessórios, têm-se titanita, zircão, apatita, epídoto primário e raros opacos; clorita e sericita resultam da alteração de biotita e plagioclásio, respectivamente.

Plagioclásio é enedral e euedral, às vezes com zonação oscilatória e patchy, sendo comum as geminações segundo as leis de albita e periclina. Biotita pode ocorrer como inclusão, às vezes marcando linhas de crescimento em cristais zonados. Kinks na geminação são freqüentes em amostras coletadas próximos a zonas de falha. Quartzo tende a ocorrer em agregados de grãos anedrais e exibem moderada extinção ondulante, às vezes recristalizados e com textura granoblástica; também ocorre em grãos intersticiais aos de plagioclásio. Microclina em geral é anedral e subedral, muitas vezes em grãos menores e intersticiais aos de plagioclásio; grãos maiores podem conter inclusões desse mineral; e pertitas e mirmequitas são pouco freqüentes e indicam cristalização num estágio pré-aquoso (Hibbard 1979). Biotita e anfibólio são geralmente intersticiais e às vezes poiquilíticos, com grãos de titanita associados e/ou inclusos. Epídoto, em grãos euedrais e subedrais, também ocorre associado a estes máficos e sua textura indica uma cristalização primária, o que, de acordo com trabalhos experimentais de Naney (1983), implicaria uma cristalização a pressões entre 6 e 8 kbar. Zircão e apatita ocorrem como inclusões, tendo-se observado em uma seção zircão 
parcialmente envolta por apatita, que indica uma cristalização um pouco mais cedo para o mesmo.

As rochas de bordo são mais ricas em feldspato potássico e têm composição de um granito sensu strictu, e são caracterizadas pela presença de egirina, que localmente pode chegar a representar mais de $15 \%$ da composição global. A única exceção é a Serra de Serrita, onde o máfico dominante é um anfibólio sódico, mas em quantidade bastante subordinada, que desta forma não apresenta uma tendência peralcalina marcante como nos outros locais. Ao contrário dos granodioritos da porção central, microclina é frequientemente pertítica e magnetita pode ser um acessório importante. Diques pegmatíticos, praticamente ausentes na porção central, são relativamente comuns nas rochas de bordo. Essas características são sugestivas de uma cristalização a fugacidades de oxigênio mais elevadas e possivelmente num estado em que o magma estava saturado com água. Alta atividade de sódio deve ter favorecido a formação de piroxênio sódico no lugar dos minerais hidratados biotita e anfibólio.

Petrograficamente, é possivel distinguir três grupos de diques. Um leucocrático, em amostra de mão semelhante aos biotita granodioritos, apesar da granulação mais fina; outro de coloração cinza, que corta estes e as rochas de bordo; e, finalmente, um terceiro de coloração azulada, com anfibólio e/ou piroxênio sódico. Os diques leucocrá. ticos têm uma composição global semelhante ao das rochas do núcleo, que indica uma relação genética. Nos diques cinza, apenas fenocristais de plagioclásio são encontrados e estão inseridos numa matriz em que microfenocristais de plagioclásio, quartzo, biotita e moscovita, possivelmente primária, estão presentes. Esses diques lembram as rochas cálcio-alcalinas (granitos tipo Conceição, de Almeida et al.
1967) intrusivas no Grupo Cachoeirinha. Os diques com piroxênio e/ou anfibólio sódico são relacionáveis às rochas peralcalinas de bordo e truncam os diques leucocráticos, mas sua relação com os diques cinza não ficou claramente estabelecida no campo. Embora estes últimos cortem as rochas de bordo, foram encontrados encraves mesocráticos lenticulares (dimensð̃es médias de $3 \times 10 \mathrm{~cm}$ ) bastante semelhantes às rochas dos diques cinza, dentro dos diques peralcalinos. Esses encraves, entretanto, podem representar xenólitos de rochas formadas num evento ígneo anterior.

GEOQUIMICA Elementos Maiores Quinze análises de elementos maiores de amostras de rochas da porção central foram apresentadas por Sial et al. (1981a, 1981b). Seis novas análises de biotita granodioritos, sete dos granitos de bordo, das quais três são de Ferreira \& Sial (1985); oito de diques; e uma de encrave mesocrático são apresentadas aqui. Essas análises, bem como as composiçðes normativas e alguns parâmetros petroquímicos delas derivadas, são mostradas nas tabelas 1,2 e 3 .

Os biotitas granodioritos são caracterizados por teores de sílica entre $67,31 \%$ e $71,3 \%$, pelos altos teores de $\mathrm{Al}_{2} \mathrm{O}_{3}$, em geral acima de $17 \%$ (o que se reflete na norma pela presença de coríndon em 13 das 21 análises) e pelo predomf. nio de $\mathrm{Na}_{2} \mathrm{O}$ sobre $\mathrm{K}_{2} \mathrm{O}$. A respeito da razão $\mathrm{Na}_{2} \mathrm{O} / \mathrm{K}_{2} \mathrm{O}$ observa-se uma certa diferença entre o Stock de Serrita e o stock SW de Serrita. No primeiro, esta razão tipicamente situa-se entre 1,8 e 2,0 (amostras SER-1 a SER-35, e S-49) enquanto no segundo valores entre 1,2 e 1,5 são os mais comuns (amostras SER-55 a SER-60, S-29, S-31 e $\mathrm{S}-65$ ). As características químicas destas rochas conferemlhes uma afinidade trondhjemítica, apesar de os teores de álcalis serem um pouco mais elevados e os de $\mathrm{CaO}$, um

Tabela 1 - Análises químicas (\%) de elementos maiores, stocks de Serrita, Pernambuco

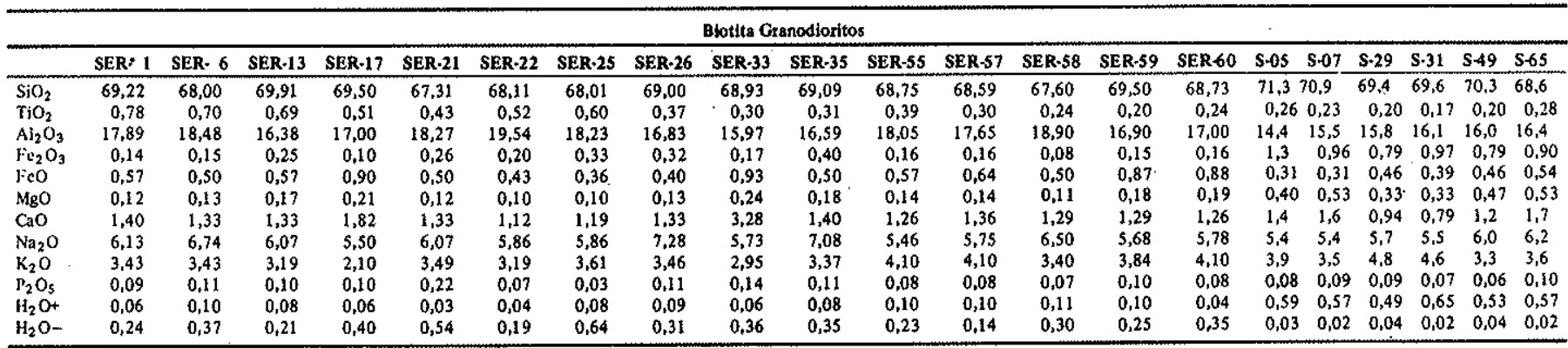

\begin{tabular}{|c|c|c|c|c|c|c|c|c|c|c|c|c|c|c|c|c|}
\hline & \multicolumn{7}{|c|}{ Egirina Granitos } & \multirow{2}{*}{\begin{tabular}{|c|} 
Encrave \\
S-49X
\end{tabular}} & \multicolumn{8}{|c|}{ Diques } \\
\hline & S.10 & $5-67$ & $S-68$ & S68A & $S M^{* *}-1$ & SM-2 & SM-3 & & $\mathrm{SD}-07 \mathrm{~S}$ & SD.0S & $S_{D^{45}}$ & Sp-55 & $\mathrm{S}_{\mathrm{D}-07 \mathrm{C}}$ & $S_{D-41}$ & $S_{D}-49$ & $\mathrm{SD} \cdot 66$ \\
\hline $\mathrm{SiO}_{2}$ & 73,00 & 74,1 & 71,5 & 71,2 & 68,10 & 71,10 & 66,00 & 65,3 & 69,2 & 70,7 & 70,5 & 70,7 & 68,2 & 68,6 & 68,4 & $\begin{array}{c}68,3 \\
0,19\end{array}$ \\
\hline $\mathrm{THO}_{2}$ & 0,16 & $<0,10$ & 0,13 & 0,24 & 0,26 & 0,30 & 0,31 & 0,30 & 0,24 & 0,20 & 0,22 & 0,14 & 0,32 & 0,20 & 0,20 & 0,19 \\
\hline $\mathrm{Al}_{2} \mathrm{O}_{3}$ & 15,4 & 13,8 & 14,4 & 14,8 & 15,30 & 14,60 & 16,60 & 15,4 & 15,5 & 15,7 & 15,7 & 15,9 & 16,2 & 15,7 & 15,8 & 16,4 \\
\hline $\mathrm{Fe}_{2} \mathrm{O}_{3}$ & 0,43 & 0,32 & 1,4 & 1,3 & 1,63 & 1,40 & 1,50 & 2,0 & 0,91 & 0,80 & 0,73 & 0,63 & 0,52 & 0,47 & 0,73 & 0,53 \\
\hline $\mathrm{FeO}$ & 0,78 & 0,15 & $<0,10$ & 0,31 & 0,58 & 0,64 & 0,57 & 0,62 & 0,62 & 0,54 & 0,78 & 0,31 & 1,24 & 0,93 & 0,78 & 0,78 \\
\hline $\mathrm{MgO}$ & 0,28 & 0,07 & 0,15 & 0,33 & 0,25 & 0,27 & 0,18 & 0,50 & 0,43 & 0,37 & 0,40 & 0,27 & 0,57 & 0,27 & 0,33 & 0,30 \\
\hline $\mathrm{CaO}$ & 1,2 & 0,49 & 0,77 & 0,87 & 0,82 & 1,00 & 0,91 & 2,1 & 0,95 & 1,3 & 1,5 & 0,90 & 1,7 & 1,2 & 1,0 & 1,1 \\
\hline $\mathrm{Na}_{2} \mathrm{O}$ & 3,7 . & 5,1 & 6,1 & 5,2 & 5,70 & 6,20 & 6,40 & 4,5 & 5,8 & 4,9 & 4,5 & 5,4 & 4,8 & 5,7 & 6,3 & $\$, 7$ \\
\hline $\mathrm{K}_{2} \mathrm{O}$ & 3,8 & 4,8 & 4,2 & 4,8 & 5,80 & 3,40 & 5,80 & 6,0 & 4,4 & 3,6 & 4,0 & 4,2 & 4,1 & 4,5 & 4,7 & 4,7 \\
\hline $\mathrm{P}_{2} \mathrm{O}_{5}$ & 0,10 & $<0,05$ & $<0,05$ & 0,09 & 0,07 & 0,07 & 0,08 & 0,25 & 0,10 & 0,08 & 0,09 & 0,08 & 0,14 & $<0,05$ & 0,06 & $<0,05$ \\
\hline $\mathrm{H}_{2} \mathrm{O}^{+}$ & 0,54 & 0,32 & 0,32 & 0,43 & 0,17 & 0,15 & 0,16 & 0,70 & 0,84 & 0,62 & 0,67 & 0,39 & 0,74 & 0,47 & 0,51 & 0,23 \\
\hline $\mathrm{H}_{2} \mathrm{O}^{-}$ & 0,04 & 0,04 & 0,04 & 0,03 & 0,34 & 0,20 & - & 0,04 & 0,03 & $0 ; 00$ & 0.05 & 0,03 & 0,01 & 0,08 & 0,04 & 0,00 \\
\hline
\end{tabular}

* SER - Sial ef al (1981a)

* * SM - Ferreira \& Sial (1985)

Notações válidas para todas as tabelas 
Tabela 2 - Normas CIPW para amostras dos stocks de Serrita, Pernambuco

\begin{tabular}{|c|c|c|c|c|c|c|c|c|c|c|c|c|c|c|c|c|c|c|c|}
\hline \multicolumn{20}{|c|}{ Blotita Granodioritos } \\
\hline & SER-1 & SER-6 & SER-13 & SER-17 & SER-21 & SER-22 & SER-25 & SER-26 & SER-33 & SER-35 & SER-55 & SER-57 & SER- 58 & SRR-59 & SER- 60 & S.0S & S-07 & S.29 & s-31 \\
\hline$Q$ & 17.28 & 12,76 & 19,42 & 24,57 & 15,85 & 19,34 & 17.11 & 10,41 & 17,97 & 12,38 & 18,10 & 15,91 & 13,48 & 18,23 & 15,76 & 21,69 & 22,98 & 15,66 & 17,76 \\
\hline c & 1.63 & 1,38 & 0,59 & 2,09 & 2,30 & 4,48 & 2,26 & - & - & - & 2,28 & 1,22 & 2,12 & 1,16 & 0,70 & 1,43 & - & - & $0 ; 61$ \\
\hline Or & 20,27 & 20,27 & 18,85 & 12,41 & 20,62 & 18,85 & 21.33 & 20,44 & 17,43 & 19,91 & 24,22 & 24,22 & 20,09 & 22,69 & 24,22 & 22,80 & 20,57 & 28,36 & 27,24 \\
\hline$A B$ & 52,05 & 57,03 & 51,36 & 46,54 & 51,36 & 49,59 & 49,59 & 61,60 & 48,49 & 59,91 & 46,38 & 48,83 & 55,18 & 48,24 & 49,09 & 45,59 & 45,59 & 48,21 & 46,64 \\
\hline $\mathrm{An}$ & 6,62 & 6,29 & 6,29 & 9,79 . & 6.03 & 5,38 & 6,61 & 3,02 & 9.15 & 3,54 & 6.32 & 6,81 & 5,49 & 6,03 & 6,34 & $\begin{array}{r}6,95 \\
6,95\end{array}$ & $\begin{array}{r}6,97,7 \\
6,95\end{array}$ & $\begin{array}{r}4,0,21 \\
3,34\end{array}$ & $\begin{array}{r}40,04 \\
3,89\end{array}$ \\
\hline Wo & - & 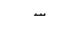 & - & - & - & - & - & 1,47 & 1,67 & 0,60 & - & $\ldots$ & - & - & - & - & 0,17 & $\begin{array}{l}0,58 \\
0\end{array}$ & - \\
\hline Di $E_{n}$ & - & - & - & - & - & - & - & 1,21 & 0,60 & 0,45 & - & - & - & - & - & - & 0,56 & 0,50 & - \\
\hline$F_{s}$ & - & - & - & - & - & - & - & 0,08 & 1,11 & 0,05 & - & - & - & - & - & - & - & - & - \\
\hline $\mathrm{Hg}_{\mathrm{B}}^{\mathrm{En}}$ & 0,30 & 0,32 & 0,42 & 1,31 & 0,30 & 0,25 & 0,25 & 1,61 & 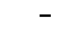 & - & 0,35 & 0,35 & 0,27 & 0,45 & 0,47 & 1,0 & 1,0 & 0,44 & 0,80 \\
\hline${ }_{W_{0}} F_{s}$ & $\overline{-}$ & - & - & $\overline{-}$ & 0,03 & 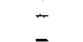 & $=$ & 0,11 & 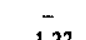 & 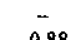 & 0,31 & 0,58 & 0,47 & 1,18 & 1,12 & - & 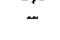 & - & - \\
\hline Mt & 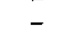 & - & - & 0,14 & $\overline{0,38}$ & 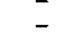 & $=$ & $\overline{0,34}$ & $\begin{array}{l}1,27 \\
0,28\end{array}$ & $\begin{array}{l}0,88 \\
0,58\end{array}$ & 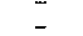 & 0,23 & 0,12 & $\overline{0,22}$ & $\overline{0,23}$ & $\overline{0,46}$ & $\overline{0,23}$ & $\overline{1.01}$ & $\tilde{0.76}$ \\
\hline I1 & 1,23 & 1,08 & 1,25 & 0,97 & 0,82 & 0,93 & 0,78 & 0,68 & 0,57 & 0,59 & 0,74 & 0,57 & 0,46 & 0,38 & 0,46 & 0,23 & 0,46 & 0,30 & 0,30 \\
\hline Hn & 0,14 & 0,15 & 0,25 & - & 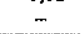 & 0,20 & 0,33 & 0,04 & - & - & 0,23 & - & - & - & m & - & 0,80 & 0,16 & 0,48 \\
\hline
\end{tabular}

\begin{tabular}{|c|c|c|c|c|c|c|c|c|c|c|c|c|c|c|c|c|c|c|}
\hline & \multicolumn{9}{|c|}{ Egirina Granitos } & \multirow{2}{*}{$\begin{array}{l}\text { Encrave } \\
\mathbf{S} 49 \mathrm{X}\end{array}$} & \multicolumn{8}{|c|}{ Diques } \\
\hline & 549 & $\mathrm{~S}-65$ & S.10 & $\begin{array}{l}567 \\
\end{array}$ & S.68 & $\$-68 \mathrm{~A}$ & SM-1 & $S M-2$ & $\mathrm{SM}-3$ & & SD-07S & SD.0S & $\mathbf{S}_{D^{-45}}$ & $\mathrm{~S}_{\mathrm{D}} \cdot 55$ & $s_{\mathrm{D}-07 \mathrm{C}}$ & $\mathrm{SD}-41$ & Sp.49 & $s_{D-66}$ \\
\hline Q & 19,56 & 15,00 & 29,64 & 24,60 & 19,20 & 22,14 & 10,99 & 18,44 & 5,07 & \begin{tabular}{|l|}
12,18 \\
\end{tabular} & 16,08 & 25,26 & 24,72 & 20,82 & 19,62 & 15,42 & 11,70 & 14,37 \\
\hline c & 0,41 & - & 3,06 & - & - & - & - & - & - & - & $\cdots$ & 1,43 & 1,12 & 0,82 & 0,82 & 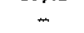 & 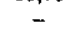 & \\
\hline Or & 19,46 & 21,13 & 22,24 & 28,36 & 25,02 & 28,36 & 20,01 & $34,19$. & 33,99 & 35,58 & 26,13 & 21,12 & 23,91 & 25,02 & 24,46 & 26,69 & 27,80 & 27,80 \\
\hline$A b$ & 50,83 & 52,40 & 31,44 & 42,97 & 50,30 & 44,02 & 55,46 & 49,16 & 55,91 & 38,25 & 49,56 & 41,40 & 38,25 & 45,59 & 40,35 & 48,21 & 53,45 & 48,21 \\
\hline An & 5,84 & 6,39 & 5,84 & 0,56 & - & 2,78 & 1,96 & - & - & 3,89 & 3,06 & 6,39 & 7,51 & 4,45 & 8,34 & 3,89 & 0,83 & 5,28 \\
\hline Wo & - & 0,81 & - & 0,23 & 0,46 & 0,70 & 0,88 & 1,14 & 0,94 & 1,39 & 0,70 & - & - & 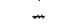 & - & 0,81 & 1,39 & 0,12 \\
\hline D: En & - & 0,70 & - & 0,20 & 0,40 & 0,60 & 0,50 & 0,65 & 0,49 & 1,20 & 0,60 & - & 0,40 & - & 1,32 & 0,30 & 0,80 & 0,05 \\
\hline Fs & - & - & - & - & - & - & 0,38 & 0,49 & 0,45 & 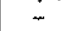 & - & - & 0,30 & - & 1,00 & 0,53 & 0,53 & 0,07 \\
\hline Hy En & 1,20 & 0,50 & 0,70 & - & - & 0,20 & 0,24 & 0,04 & - & - & 0,50 & 0,90 & 0,70 & 0,70 & 0,40 & 0,40 & - & 0,55 \\
\hline${ }^{k y} F_{s}$ & 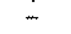 & 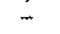 & 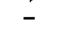 & - & - & & 0,19 & 0,03 & - & - & 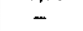 & - & - & 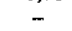 & - & 0,53 & - & 0,73 \\
\hline Wo & - & - & - & 0,58 & 1,16 & - & - & - & 0,52 & 1,28 & - & - & - & - & - & 2 & 0,35 & - \\
\hline Mt & 1,01 & 1,01 & 2,02 & - & - & 0,25 & 0,86 & 0,78 & 0.67 & 1,16 & 1,39 & 1,16 & 1,16 & 0,46 & 0,70 & 0,70 & 1,16 & 0,70 \\
\hline I & $\begin{array}{r}0,30 \\
0,16\end{array}$ & 0,46 & 0,31 & $=$ & - & 0,30 & 0,42 & 0,36 & 0,43 & 0,61 & 0,30 & 0,30 & 0,46 & 0,30 & 0,61 & 0,30 & 0,30 & 0,30 \\
\hline & & & 0,26 & 0,32 & 1,10 & 1,12 & 0,40 & 0,21 & 0,37 & 1,12 & - & - & - & 0,32 & - & - & - & - \\
\hline
\end{tabular}

Tabela 3 - Alguns parâmetros petroquimicos para amostras dos stocks de Serrita, Pernambuco

\begin{tabular}{|c|c|c|c|c|c|c|c|c|c|c|c|c|c|c|c|c|c|c|c|}
\hline & & \multicolumn{18}{|c|}{ Biotita Granodiontios } \\
\hline & SER-1 & SER-6 & SER-13 & SER-17 & SER-21 & SER-22 & SER-25 & SER-26 & SER-33 & SER-35 & SER-55 & SER.57 & SER-58 & SER-59 & SER-60 & S-05 & 507 & \$-29 & $8-31$ \\
\hline$\frac{\pi}{b}$ & $\begin{array}{l}25,68 \\
65,24\end{array}$ & $\begin{array}{l}24,13 \\
67,88\end{array}$ & $\begin{array}{l}24,64 \\
67,14\end{array}$ & $\begin{array}{l}18,05 \\
67,70\end{array}$ & $\begin{array}{l}26,43 \\
65,84\end{array}$ & $\begin{array}{l}25,54 \\
67,18\end{array}$ & $\begin{array}{l}27,51 \\
63,96\end{array}$ & $\begin{array}{l}23,65 \\
71,86\end{array}$ & $\begin{array}{l}23,22 \\
64,59\end{array}$ & $\begin{array}{l}23,88 \\
7,87\end{array}$ & $\begin{array}{l}31,49 \\
60,30\end{array}$ & 30,33 & 24,57 & $\begin{array}{l}29,48 \\
62,68\end{array}$ & 30,41 & 28,02 & 30,26 & 35,49 & 35,02 \\
\hline In & 8,38 & $\begin{array}{r}7,49 \\
7,7\end{array}$ & B,22 & 14,24 & 7.73 & 7,28 & & & 1 & & & & & $\pi$ & & & 23 & 8 & $\begin{array}{l}5,01 \\
5,1\end{array}$ \\
\hline & 19,2 & & & 29 & 18,48 & 22,04 & 19 & & & & & & & & & & & & 19,38 \\
\hline & 22,62 & a & & & & 21 & & & & & & & & & & & & &, 73 \\
\hline $\mathbf{A b}$ & 58,09 & 63,33 & 57,30 & 55,72 & 58,48 & 56,49 & 56,3 & 66,62 & 57,8 & 64,9 & 52,2 & 54, & 62,1 & 54, & 55, & 50,61 & 51,14 & 52,27 & 50,89 \\
\hline $\mathrm{Va}+\mathrm{K} \mathrm{c}$ & a)) 7 & 0,80 & 0,82 & 0,67 & 0,75 & 0,67 & 0,74 & 0,93 & 0,79 & 0,92 & 0,75 & 0,75 & 0,76 & 0,89 & 0,82 & 0.77 & 0,83 & 0.92 & 0,87 \\
\hline$a_{2} \mathrm{O}$ & 1,79 & 1,97 & 1,90 & 2,6 & 1,74 & 1,80 & 1,62 & 2,10 & 1,94 & 2,10 & 1,33 & 1,40 & 1,90 & 1,48 & 1,41 & 1,38 & 1,54 & 1,19 & 1,20 \\
\hline
\end{tabular}

\begin{tabular}{|c|c|c|c|c|c|c|c|c|c|c|c|c|c|c|c|c|c|c|}
\hline & & \multicolumn{8}{|c|}{ Egirina Granitos } & \multirow{2}{*}{\begin{tabular}{|l|} 
Encrave \\
S-19X \\
\end{tabular}} & \multicolumn{8}{|c|}{ Diques } \\
\hline & $\$-49$ & $8-65$ & $\$-10$ & S.67 & S-68 & $868 \mathrm{~A}$ & SM-1 & SM.2 & SM-3 & & $\mathrm{s}_{\mathrm{D}-07 \mathrm{~s}}$ & Sp-05 & $5 \mathrm{sp} 45$ & $\mathrm{Sp} \cdot 5 \mathrm{~s}$ & Spo-07C & $\mathrm{sp}-41$ & $\mathrm{sp-49}$ & 8066 \\
\hline Or & 25,56 & 26,44 & 37,37 & 39,45 & 33,22 & 37,73 & 42,47 & 26,96 & 39,22 & 45,78 & 33,18 & 30,65 & 34,32 & 33,33 & 33,44 & 33,87 & 33,87 & 34,20 \\
\hline${ }_{A n}^{A b}$ & $\begin{array}{r}68,77 \\
7,67\end{array}$ & $\begin{array}{r}65,57 \\
7,99\end{array}$ & $\begin{array}{r}52,82 \\
9,81\end{array}$ & $\begin{array}{r}59,77 \\
0,78\end{array}$ & $\begin{array}{c}66,78 \\
-\end{array}$ & $\begin{array}{r}58,57 \\
370\end{array}$ & 57,53 & $\begin{array}{r}70,40 \\
2,64\end{array}$ & 60,78 & $\begin{array}{l}49,21 \\
501\end{array}$ & 62,93 & 60,08 & 54,90 & 60,74 & 55,16 & 61,19 & 65,12 & 59,30 \\
\hline $\mathrm{Qz}$ & 21,97 & 16,94 & $\begin{array}{r}35,01 \\
35,57\end{array}$ & $\begin{array}{r}0,10 \\
25,64\end{array}$ & 20,31 & $\begin{array}{r}3,4,0 \\
23,42\end{array}$ & $\overline{12,85}$ & $\begin{array}{r}21,04 \\
21,59\end{array}$ & $\overline{5,93}$ & $\begin{array}{r}3,01 \\
14,16\end{array}$ & $\begin{array}{r}3,89 \\
17,52\end{array}$ & $\begin{array}{r}9,21 \\
28,78\end{array}$ & $\begin{array}{l}10,78 \\
28,45\end{array}$ & $\begin{array}{r}5,93 \\
22,77\end{array}$ & 11,40 & 4,94 & 1,01 & 6,50 \\
\hline Or & $.21,85$ & 23,87 & 26,69 & 29,56 & 26,47 & 30,00 & $\begin{array}{l}1, \infty, 3 \\
37,02\end{array}$ & 21 & 36, & \begin{tabular}{|l}
14 \\
41
\end{tabular} & 28,46 & $\begin{array}{l}28,06 \\
24,06\end{array}$ & $\begin{array}{l}28,45 \\
27,52\end{array}$ & $\begin{array}{l}22,17 \\
27,37\end{array}$ & $\begin{array}{l}23,24 \\
28,97\end{array}$ & $\begin{array}{l}17,07 \\
29,55\end{array}$ & 12,59 & 15,90 \\
\hline $\mathbf{A b}$ & 57,08 & 59,19 & 37,73 & 44,79 & 53,22 & 46,58 & 50,14 & 56,70 & 57,17 & 44,47 & $\$ 4,02$ & 47,16 & 44,03 & 49,86 & 47,79 & 53,38 & $\begin{array}{l}27,91 \\
57,50\end{array}$ & 53,34 \\
\hline$\underset{\mathrm{Al}}{\mathrm{Na}+\mathrm{K}(\mathrm{mol})}$ & 0,84 & 0,86 & 0,66 & 0,99 & 1,01 & 0,93 & 1,02 & 0,95 & 1,01 & 0,91 & 0,93 & 0,76 & 0,75 & 0,85 & 0,91 & 0,91 & 0,98 & 0,88 \\
\hline $\begin{array}{c}\mathrm{Na}_{2} \mathrm{O} \\
\mathrm{K}_{2} \mathrm{O}\end{array}$ & 1,82 & 1,72 & 0,97 & 1,06 & 1,45 & 1,08 & 0,98 & 1,82 & 1,10 & 0,75 & 1,32 & 1,36 & 1,12 & 1,33 & 1,17 & 1,27 & 1,34 & 1,21 \\
\hline
\end{tabular}

segundo a definição de Barker (1979). Quando plotadas no pouco inferiores às concentraçðes típicas de trondhjemitos diagrama Ab-An-Or (Barker, op. cit., modificado de O'Connor 1965), todas as amostras do Stock de Serrita caem dentro do campo das rochas tronhjemíticas enquanto as amostras do stock $\mathrm{SW}$ de Serrita (com exceção da SER-58), juntamente com a única amostra do stock menor (S-07), situam-se dentro do campo dos granitos, embora bastante próximas ao limite entre os dois grupos (Fig. 2).

Os granitos nos bordos dos stoks têm em média valores de sílica mais elevados e de alumina mais baixos que os dos biotita granodioritos. As razões $\mathrm{Na}_{2} \mathrm{O} / \mathrm{K}_{2} \mathrm{O}$ também são mais baixas, com os valores mais elevados sendo de $1,6 \mathrm{e}$ 1,82 e os mais baixos aproximando-se da unidade. Com exceção da amostra SM-2, todas as demais plotam dentro do campo granito no diagrama Ab-An-Or (Fig. 2).

Os biotita granodioritos são meta a paraluminosos e possuem índices agpaíticos entre 0,67 e 0,93. Os granitos de bordo têm tendência peralcalina, com índices agpaíticos entre 0,93 e 1,02. A única exceção é a amostra S-10, cujo índice agpaítico é 0,66 , o qual, porém, deve refletir mais a química dos feldspatos que ser uma característica da rocha, já que o índice de cor desta amostra é inferior a 3.

Das oito análises de rochas de diques, quatro provêm de diques leucocráticos $\left(\mathrm{SD}_{\mathrm{D}}-05, \mathrm{SD}-075, \mathrm{SD}_{\mathrm{D}}-45\right.$ e $\left.\mathrm{SD}-55\right)$, duas de diques cinza ( $\mathrm{SD}_{\mathrm{D}}$-07C e SD-41) e duas de diques com piroxênio e/ou anfibólio sódico (SD-49 e SD-66). Esses grupos de diques podem ser separados com base nos teores de 


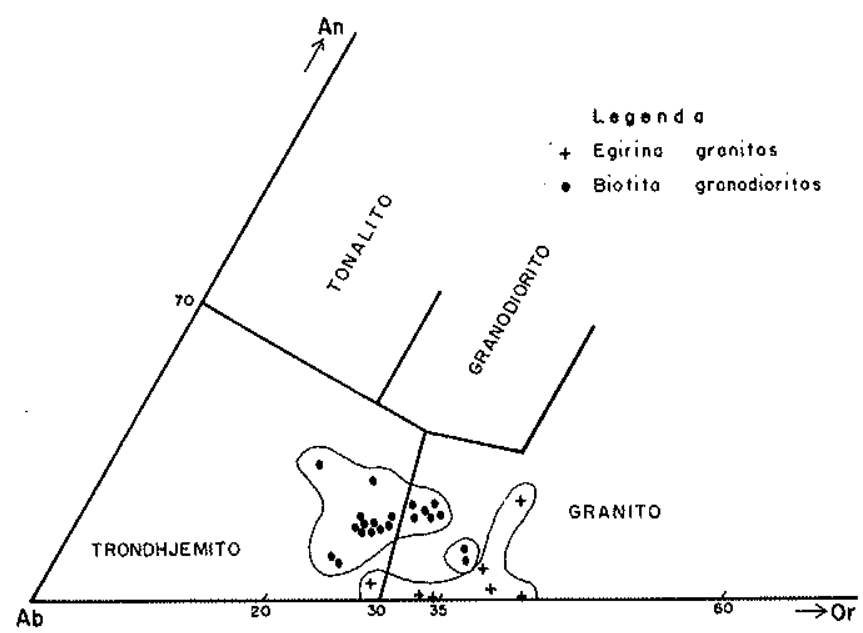

Figura 2 - Composições normativas dos biotita granodioritos e dos egirina granitos no diagrama $A b-O r-A n$, onde estão plotados os campos de algumas rochas plutônicas (seg. Barker 1979, modificado de O'Connor 1965)

$\mathrm{SiO}_{2}, \mathrm{CaO}$ e $\mathrm{MgO}$ e na razão $\mathrm{Fe}_{2} \mathrm{O}_{3} / \mathrm{FeO}$. Os diques leucocráticos tem teores de $\mathrm{SiO}_{2}$ e a razão $\mathrm{Fe}_{2} \mathrm{O}_{3} / \mathrm{FeO}$ mais elevados que os dos outros dois grupos e exibem uma variação no índíce agpaítico igual ao dos biotita granodioritos. Os diques cinza têm valores de $\mathrm{MgO}$ e $\mathrm{CaO}$ algo mais elevados e a razão $\mathrm{Fe}_{2} \mathrm{O}_{3} / \mathrm{FeO}$ mais baixa que os de diques com piroxênio sódico. Nestes últimos, os valores do índice agpaítico são os mais elevados $(0,88$ e 0,98$)$, o que lhes confere uma tendência peralcalina.

A análise do encrave mesocrático é a única em que o teor de $\mathrm{K}_{2} \mathrm{O}$ supera o de $\mathrm{Na}_{2} \mathrm{O}$ e são encontrados os valores mais baixos de $\mathrm{SiO}_{2}(65,3 \%)$ e mais elevados de $\mathrm{CaO}(2,1 \%)$. Possivelmente trata-se de um xenólito resultante de um evento ígneo anterior já que quimicamente difere da composição dos diques cinza.

Elementos-traços Cinco amostras de biotita granodioritos e quatro de granitos peralcalinos foram analisadas para $\mathrm{Rb}, \mathrm{Sr}, \mathrm{Th}, \mathrm{Ta}, \mathrm{Nb}, \mathrm{Hf}, \mathrm{Y}, \mathrm{Zr}$, Sn e Ba. As amostras de diques foram também analisadas para esses mesmos elementos. Três análises de $\mathrm{Rb}, \mathrm{Sr}, \mathrm{Nb}, \mathrm{Y}, \mathrm{Zr}$ e Ba para amostras das serras dos Macacos e da Vassoura são apresentadas por Ferreira e Sial (1985) e também utilizadas. Esses resultados encontram-se na tabela 4 . Normalizando esses valores em relação a um granito de cadeia oceânica hipotético (Pearce et al. 1984) e plotando-os contra os elementos ordenados de acordo com sua incompatibilidade relativa durante a geração de basaltos mesoceânicos (Figs. $3 a$ e $3 b$ ), os padrões obtidos para os granodioritos e granitos são semelhantes e caracterizados por uma forte anomalia de Ba e pelos baixos teores de $\mathrm{Zr}, \mathrm{Sn}, \mathrm{Y}$ e $\mathrm{Yb}$. Isso indica claramente que esses dois grupos de rocha foram formados pelo processo de acumulação de cristais e assim sua química não reflete a com* posição do material inicial e, sim, do material acumulado. Dessa forma, os diagramas de Pearce et al. (op. cit.) não podem ser utilizados neste caso para a interpretação do ambiente tectônico.

A única diferença significativa em termos de elementos-traços entre as rochas de bordo e do núcleo diz respeito aos teores de $\mathrm{Sr}$, mais elevados nos granodioritos que nos
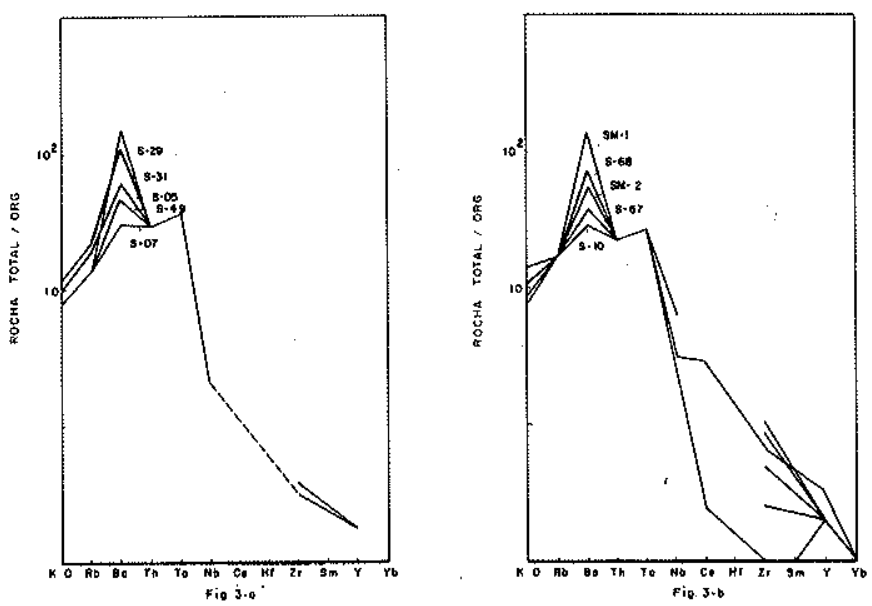

Figura 3 - Padrões geoquimicos normalizados em relação a um granito de cadeia oceânica hipotético (Pearce et al. 1984) de análises de elementos-traços de granodioritos (a) e granitos (b) dos stocks de Serrita

granitos, enquanto $\mathrm{Nb}, \mathrm{Zr}$ e $\mathrm{Y}$ tendem a ser mais elevados nas rochas de bordo que nos biotita granodioritos. Este é o comportamento que seria de esperar, caso os granodioritos tivessem resultado da acumulação de cristais num líquido mais básico que aquele do qual os granitos foram formados.

Os grupos de diques analisados são indistinguíveis $\mathrm{em}$ termos do comportamento de elementos-traços e caracterizados pelos elevados teores de $\mathrm{Sr}$, superiores aos dos granitos de bordo e comparáveis ao dos granodioritos.

Os padrões de elementos terras-raras (TR) para quatro amostras dos biotita granodioritos foram apresentados por Sial (1984a) e acham-se reproduzidos na figura 4. As curvas diferem principalmente nas proporçōes relativas dos terrasraras leves mas o padrão é o mesmo para todas as amostras, isto é, caracteriza-se pelo enriquecimento em terras-raras leves comparado ao condrito pelo forte empobrecimento em terras-raras pesadas e por uma discreta anomalia positiva de Eu. Parece haver uma relação negativa com os valores de $\delta \mathrm{O}^{18}$. (entre parênteses na Figura 4) e uma positiva com os de $\mathrm{SiO}_{2}$. Os padrões são semelhantes aos encontrados em tonalitos, trondhjemitos, quartzo diorito e granodioritos pré-cambrianos (Cullers \& Graf 1984), e poderiam ser gerados por fusão parcial de uma fonte anfibolítica, eclogítica ou granada anfibolítica, em que anfibólio e/ou granada ficariam no resíduo da fusão. Padrōes similares poderiam ser gerados por processo de fracionamento, porém a ausência de cumulados mais básicos favorece o modelo de fusão parcial.

Padrões de distribuição de elementos terras-raras para rochas de bordo, uma na Serra de Serrita (S-10), outra da serra no bordo sul do stock de Serrita (S-67) e outra na Serra do Boqueirão (S-68) são mostrados na Figura 5. Nas serras de Serrita e do Boqueirão, os padrões são paralelos, embora o LTR seja cerca de duas vezes maior na Serra do Boqueirão. São caracterizados pelo enriquecimento em terras-raras leves e empobrecimento em terras-raras pesadas, quando comparados com a média dos condritos e pela ausência de uma anomalia de Eu. Esses padrões diferem daqueles dos granodioritos pela ausência da anomalia de Eu e pelos teores um pouco mais elevados de terras-raras pesa- 


\begin{tabular}{|c|c|c|c|c|c|c|c|c|c|c|c|c|c|c|c|c|c|c|c|c|}
\hline & \multicolumn{5}{|c|}{ Biotita Granodioritos } & \multicolumn{7}{|c|}{ Egirina Granitos } & \multicolumn{8}{|c|}{ Diques } \\
\hline & s-05 & s-07 & S-29 & S-31 & s-49 & SM-1 & SM-2 & SM-3 & S-10 & S-67 & S-68 & S.68A & $\mathrm{S}_{\mathrm{D}^{-7 \mathrm{~S}}}$ & $\mathrm{~S}_{\mathrm{D}-05}$ & $\mathrm{SD}_{\mathrm{D}} 45$ & $\mathrm{~S}_{\mathrm{D}-55}$ & $\mathrm{SD}_{\mathrm{D}}-7 \mathrm{C}$ & $\mathrm{S}_{\mathrm{D}-41}$ & $\mathrm{~S}_{\mathrm{D}}-49$ & SD-66 \\
\hline $\mathrm{Rb}$ & 81 & 65 & 65 & 91 & 64 & 78 & 75 & 75 & 72 & - & 80 & 140 & 72 & 72 & 73 & 79 & 64 & 73 & 69 & 73 \\
\hline Sr & 2.400 & 1.800 & 3.700 & 3.000 & 2.700 & 760 & 1.660 & 1.820 & 2.300 & - & 1.180 & 980 & 3.000 & 3.200 & 3.080 & 2.800 & 3.000 & 3.200 & 3.400 & 3.600 \\
\hline Th & $<25$ & $<25$ & $<25$ & $<25$ & $<25$ & - & - & - & $<25$ & - & $<25$ & & $<25$ & $<25$ & $<25$ & $<25$ & $<25$ & $<25$ & $<25$ & $<25$ \\
\hline $\mathrm{Ta}$ & $<25$ & $<25$ & $<25$ & $<25$ & 2 & - & - & - & $<25$ & - & $<25$ & $<25$ & $<25$ & $<25$ & $<25$ & $<25$ & $<25$ & $<25$ & $<25$ & $<25$ \\
\hline $\mathrm{Nb}$ & $<20$ & $<20$ & $<20$ & 29 & $<20$ & 28 & 52 & 29 & $<20$ & $<20$ & 30 & 36 & $<20$ & $<20$ & $<20$ & $<20$ & $<20$ & $<20$ & 20 & 30 \\
\hline Hf & $<200$ & $<200$ & $<200$ & $<200$ & $<200$ & - & - & - & $<200$ & $<200$ & $<200$ & $<200$ & $<200$. & $<200$ & $<200$ & $<200$ & $<200$ & $<200$ & $<200$ & $<200$ \\
\hline $\mathrm{Y}$ & $<10$ & $<10$ & $<10$ & $<10$ & $<10$ & $<10$ & $<10$ & $<10$ & $<10$ & 11 & $<10$ & $<10$ & $<10$ & $<10$ & $<10$ & $<10$ & $<10$ & $<10$ & $<10$ & $<10$ \\
\hline $\mathrm{Zr}$ & 126 & 114 & 118 & 114 & 128 & 210 & 360 & 74 & 126 & 28 & 280 & 260 & 120 & 132 & 140 & 124 & 148 & 180 & 196 & 210 \\
\hline Sn & $<5$ & $<5$ & $<5$ & $<5$ & $<5$ & - & - & - & $<5$ & $<5$ & $<5$ & $<5$ & $<5$ & $<5$ & $<5$ & $<5$ & $<5$ & $<5$ & $<5$ & $<5$ \\
\hline $\mathrm{Ba}$ & 3.300 & 1.800 & 7.400 & 5.800 & 2.700 & 6.900 & 3.700 & 6.800 & 528 & 2.200 & 4.000 & 1.900 & 4.100 & 5.500 & 4.300 & 5.300 & 5.100 & 4.700 & 5.400 & 5.900 \\
\hline
\end{tabular}

- elemento não determinado

\section{Tabela 4 - Análises quimicas (ppm) de elementos-traços de amostras dos stocks de Serrita, Pernambuco}

dos. Uma formação dessas rochas a partir do mesmo material que gerou os granodioritos parece plausível. Caso o material que gerou estes últimos esteja cristalizando plagioclásio, os teores de Eu no líquido remanescente diminuem e os dos terras-raras aumentam, já que o Eu pode ser acomodado na estrutura do plagioclásio mas não os terras-raras pesados. Se o líquido residual cristaliza para produzir os granitos, os padrões de terras-raras nessas rochas tenderiam a não exibir uma anomalia positiva de Eu e possuiram valores de TR pesados mais elevados que os granodioritos; estes últimos

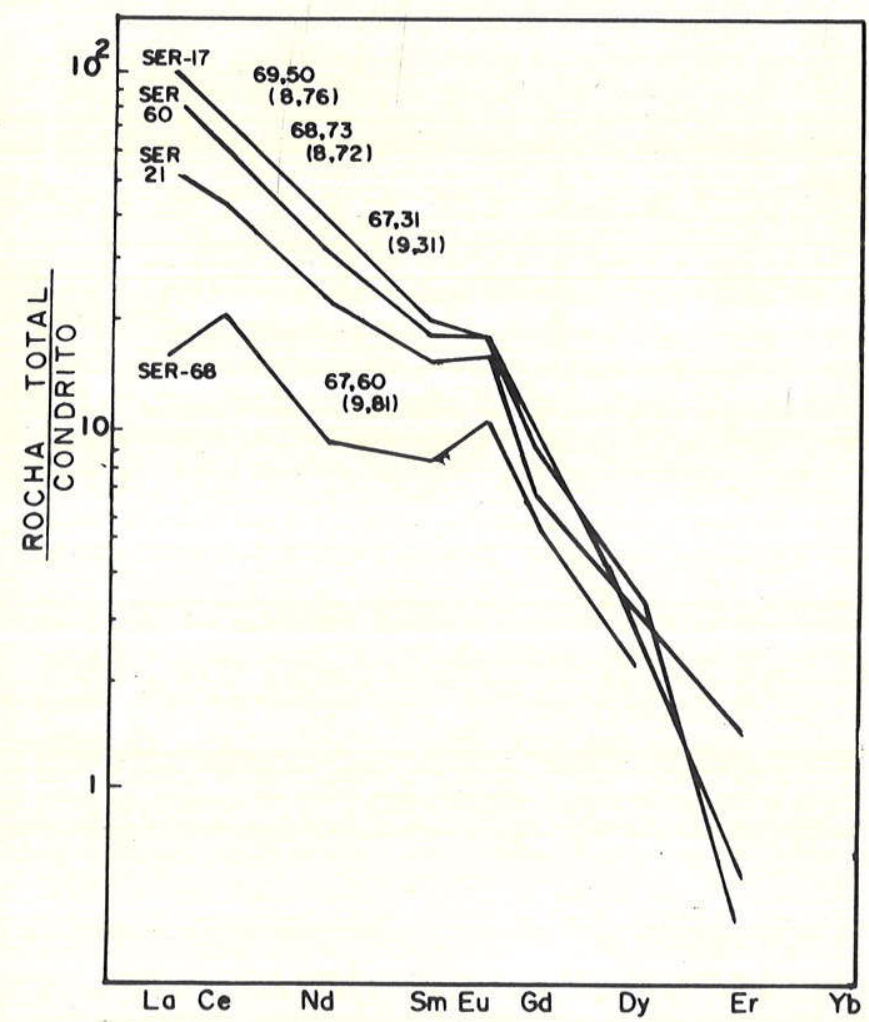

Figura 4 - Padrões de distribuição de elementos terras-raras para granodioritos dos stocks de Serrita (Sial 1984a). O número em parênteses refere-se ao valor de $\delta O^{18}$ da amostra e o outro a seu teor de $\mathrm{SiO}_{2}$

poderiam ser acomodados na estrutura dos anfibólios e piroxênios. A amostra da serra no bordo sul do Stock de Serrita mostra um somatório de terras-raras muito inferior ao das outras duas amostras e uma anomalia de Eu. Os elementos terras-raras em rochas graníticas são acomodados principalmente nos minerais acessórios (Hanson 1980) e os valores obtidos para a amostra S-67 parecem resultar da incapacidade do método empregado para solubilizar esses minerais, o que é corroborado pelos baixos teores de zircônio encontrados para esta amostra (cerca de 10 vezes menor que nas demais rochas de bordo) e de $\mathrm{P}_{2} \mathrm{O}_{5}(<0,05 \%)$, o que indica que os terras-raras presentes no zircão e apatita não contribuíram para o padrão obtido.

Os padrões de terras-raras para as rochas diques (Fig. 6) são semelhantes, embora a amostra do dique cinza $\left(\mathrm{SD}_{\mathrm{D}}\right.$-07C) apresente somatório de terras-raras mais elevado que nos diques leucocráticos. As razões $\mathrm{Ce} / \mathrm{Yb}$ nos diques leucocráticos são intermediárias nos valores encontrados para os granodioritos (mais elevados) e as rochas de bordo (mais baixos) e sugerem sua formação num estágio também intermediário aos que originaram esses dois grupos de rochas.

Isótopos de oxigênio Médias para a composição de isótopos de oxigênio em rocha total para 15 amostras de granodiorito do corpo de Serrita, uma do stock menor e seis do stock SW de Serrita, além de uma de egirina granito (Serra dos Macacos), foram reportadas por Sial (1984b). O padrão de distribuição dos valores de $\delta 0^{18}$ dentro dos plutões é apresentado e interpretado utilizando-se. os dados inéditos desse autor, e mostrado na figura 7.

Valores de $\delta 0^{18}$ no Stock de Serrita variam de $8,45^{\circ} \%_{00}$ a $9,69^{\circ} \%$ com média de $9,23^{\circ} \%$, próxima ao valor da determinação realizada no stock menor $\left(9,17^{\circ} \% 0\right)$. Cinco amostras do corpo SW de Serrita deram valores entre $8,72 \%$ e $9,81 \%$, com média de $9,43 \%$, e uma forneceu um valor anômalo bastante elevado, $11,37 \%$. Um dos valores mais elevados foi encontrado na Serra dos Macacos $\left(9,66^{\circ} / 0_{0}\right)$.

As curvas de isovalor no Stock de Serrita mostram um pequeno mas consistente aumento nos valores de $\delta \mathrm{O}^{18}$ para a porção centro-oeste do corpo e são alongadas na direção SW-NE. O menor número de determinações no stock SW de Serrita permite apenas um esboço das isolinhas, mas o padrão obtido é semelhante ao do Stock de Serrita. O alongamento das curvas na direção SW-NE concorda com a direção da xistosidade nos micaxistos encaixantes e com uma direção principal de fraturamento. Assim, a interação das rochas dos stocks com as encaixadas ou com águas meteóricas através de sistemas de fraturas deve ser considerada para explicar os padrões obtidos.

Rochas graníticas com baixos valores de $\delta \mathrm{O}^{18}$ produzidos por interação com grandes quantidades de águas meteóricas são encontradas nas porções epizonais de muitos batólitos (Taylor 1977). No caso presente, como a maior intensidade de fraturamento se dá próximo ao bordo dos stocks, 


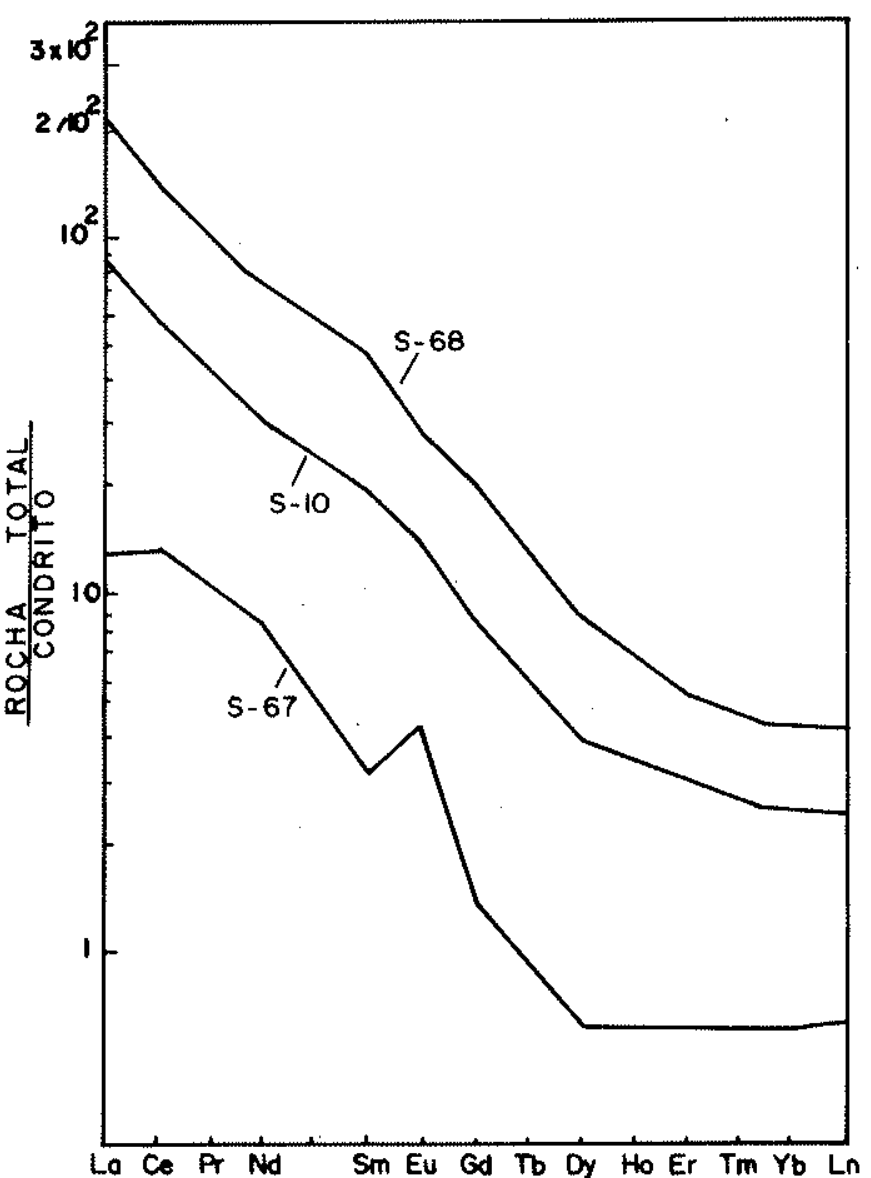

Figura 5 - Padrões de distribuição de elementos terras-raras para granitos peralcalinos dos stocks de Serrita

este seria um processo capaz de provocar uma diminuição nos valores de $\delta \mathrm{O}^{18}$,nos bordos em relação aos valores das porções centrais. Quanto maior a profundidade de colocação de um plutão, porém, menor será a possibilidade de atuação de um tal processo e, como os corpos em estudo não exibem características de colocação a profundidades rasas, esta possibilidade pode ser rejeitada com certa segurança.

Barker et al. (1976) mediram a composição isotópica de um grande número de trondhjemitos e encontraram valores de $\delta 0^{18}$ entre $5,2 \%$ e $8,9^{\circ} \%$ em amostras isotopicamente não-perturbadas. Embora os granodioritos deste estudo não possam ser considerados trondhjemitos típicos, eles apresentam características em comum com essas rochas e, por isso, os valores de $\delta \mathrm{O}^{18}$ mais elevados encontrados sugerem que o magma sofreu alteração isotópica pela interação com as rochas pelíticas encaixantes. Dois processos podem ser responsáveis: a) assimilação da rocha encaixante de $\delta \mathrm{O}^{18}$ mais alto [uma determinação nos micaxistos Salgueiro por Sial (1984b) forneceu um valor de 13,72\% $\%$ ]; e b) quebra das fases hidratadas das encaixantes devido ao aquecimento magmático, que proporciona ao magma água rica em $\delta \mathrm{O}^{18}$. Esta segunda hipótese parece mais provável $\mathrm{em}$ vista da :ausência de xenólitos e foi defendida por Arth $e t$ al (1978) para explicar as características isotópicas da suíte gabro-diorítica-tonalítica-trondhjemítica do sudoeste da Finlândia. $\mathrm{O}$ valor de $\delta \mathrm{O}^{\mathrm{tB}}$ relativamente mais elevado na Serra dos Macacos poderia resultar de uma superposição dos dois fatores mencionados, pois nesta xenólitos estão presentes.

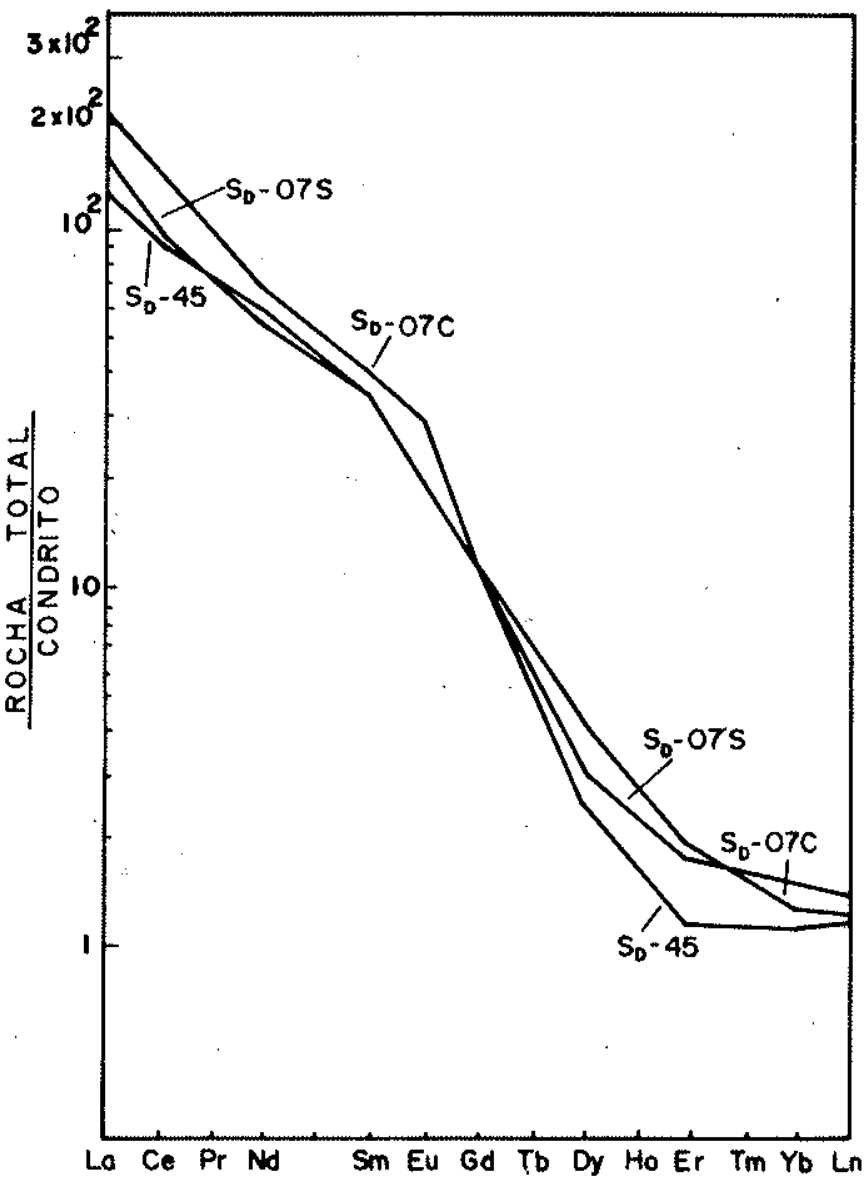

Figura 6 - Padrões de distribuição de elementos terras-raras para alguns diques que cortam os stocks de Serrita

CURVAS dE ISOVALOR DE $\delta O^{18}$ NOS STOCKS DE SERRITA - PE

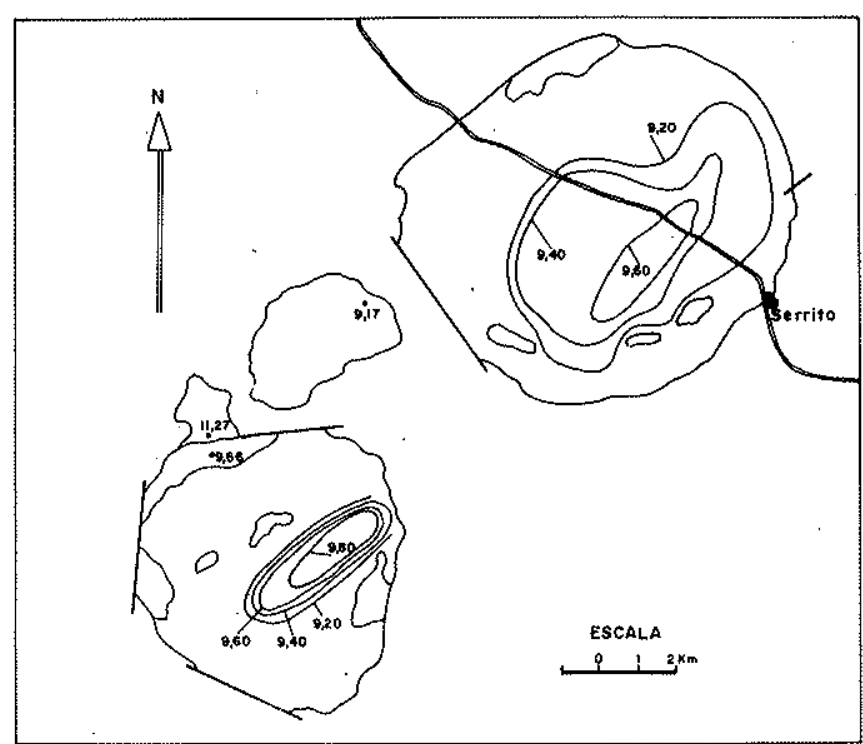

Figura 7 - Curvas de isovalor de $\delta O^{18}$ para granodioritos dos stocks de Serrita e a SW de Serrita. São mostrados ainda os valores de $\delta O^{18}$ no stock menor e na Serra dos Macacos

DISCUSSÃo Zen \& Hammarstron (1984) e Zen (1985), baseados em resultados experimentais de fusōes granodioríticas sintéticas (Naney 1983), têm defendido que a 
existência de epídoto magmático nos granitos do noroeste da América do Norte evidencia uma cristalização sob pressões litostáticas entre 6 e $8 \mathrm{kbar}$. A evidência textural indica que o epídoto presente nos biotita granodioritos dos stocks de Serrita também tem uma origem magmática. Juntamente com este fator, a ausência de metamorfismo de contato nas rochas encaixantes também apóia uma colocação relativa. mente profunda para essas rochas. A quase ausência de texturas pertíticas e mirquequíticas sugere que a cristalização se deu num estágio pré-aquoso (Hibbard 1979), porém água deve ter estado presente em concentraçōes relativamente elevadas, pois os estudos experimentais de Naney (1983) demonstraram que um mínimo de aproximadamente $3 \%$ de $\mathrm{H}_{2} \mathrm{O}$ em sistemas granodioríticos a $8 \mathrm{kbar}$ é necessário para a cristalização de hornblenda e que a estabilidade termal máxima de epídoto se dá em condições đe saturação em água.

Derivação por fusão parcial de uma fonte granada anfibolítica para os granodioritos, nos quais granada ficou retida no resíduo da fusão, é coerente com os padrões de terras-raras obtidos e responderia tanto por seu caráter trondhjemítico rico em alumina (Barker 1979) como pela presença de água no magma derivado, parte da qual poderia provir das encaixantes, como já se discutiu. Zonação oscilatória no plagioclásio pode indicar que correntes de convecção estiveram atuantes durante a cristalização do magma, o que é favorecido pela diminuição de viscosidade provocada pela presença de fases voláteis (Pitcher 1979). O caráter intersticial de biotita e anfibólio resulta de uma cristalização tardia desses minerais, embora biotita tenha experimentado um período de cristalização mais prolongado, já que ocorre como inclusões em plagioclásio. Com o decorrer da cristalização, a concentração de água foi aumentada até que epídoto se tornou uma fase estável.

O padrão de elementos-traços das rochas (Fig. 3a) traduz o comportamento de um sólido e não de um líquido. Como os stocks foram profundamente arrasados, o que se vê hoje deve ser a parte inferior da intrusão, o que explica a ausência de produtos resultantes da cristalização de fases fluidas.

Os valores de $\delta \mathrm{O}^{18}$ relativamente elevados também poderiam resultar da colocação profunda da intrusão porque a diferença de temperatura entre ela e as encaixantes não seria muito grande e favoreceria a interação do magma com as fases minerais hidratadas das encaixantes.

$\mathrm{Zr}, \mathrm{Hf}, \mathrm{Nb}, \mathrm{Ta}, \mathrm{Y}, \mathrm{U}$ e Th nos granitos peralcalinos dos stocks de Serrita têm concentrações muito mais baixas que em muitos granitos peralcalinos (Bowden \& Tumer 1974), embora comparáveis a granitos peralcalinos da Arábia Saudita (Harris \& Morriner 1980). Diferem desses últimos, no entanto, por suas concentrações extremamente elevadas de Sr. $O$ padrão de terras-raras nos granitos de Serrita também difere do encontrado em outras partes do mundo (por exemplo, Bowden \& Whitley 1974). Uma origem na crosta superior por fusão parcial de rochas graniticas do embasamento, provocada pela ascensão na crosta de magmas basálticos, foi defendida por Bowden \& Turner (1974) para os granitos peralcalinos do Níger e da Nigéria, mas, como os padrőes de elementos-traços e terras-raras nos granitos peralcalinos diferem do destas rochas, sua gênese também deve ser distinta.

Os teores dos elementos maiores e traços nos granitos peralcalinos e nos biotita granodioritos são bastante semelhantes, sendo que a principal diferença química entre eles resi- de na razão $\mathrm{Na}_{2} \mathrm{O} / \mathrm{K}_{2} \mathrm{O}$ e nos tteores de $\mathrm{Al}_{2} \mathrm{O}_{3}$ (mais elevados nos granodioritos). Assim, os dados disponíveis sugerem uma relação genética entre essas rochas. Rápido soerguimento crustal num estágio, em que grande parte do magma já tivesse cristalizado para gerar os granodioritos, faria com que o material parcialmente solidificado perdesse sua fase volátil e pudesse então migrar na crosta. $O$ liquido remanescente tenderia a migrar para os bordos da intrusão, onde finalmente cristalizaria para gerar os granitos peralcalinos. $O$ caráter peralcalino dos granitos seria adquirido pela diminuição nos teores de $\mathrm{Al}_{2} \mathrm{O}_{3}$ e pela elevação nos teores de $\mathrm{K}_{2} \mathrm{O}$ no líquido residual, já que a evidência textural indica que, nos granodioritos, plagioclásio foi o primeiro mineral essencial a cristalizar. Outra possibilidade seria a geração dos granitos peralcalinos a partir da refusão dos biotita gra. nodioritos devido também a um soerguimento crustal rápido, o que poderia fazer o granodiorito interceptar seu solidus (Hall 1971, propôs que fusão crustal pode resultar da queda da pressão em consequiência de um rápido soerguj. mento). As relações de volume mostram que apenas uma pequena porcentagem de fusão seria requerida, não sendo necessária assim uma elevação de temperatura substancial acima dos solidus. Os padrőes de distribuição de elementostraços e terras-raras encontrados nos granitos são os esperados, caso sua relação genética com os granodioritos seja admitida (embora pela segunda possibilidade fosse de esperar uma anomalia negativa de Eu no padrão de terras-raras) e sua dissimilaridade com o padrão obtido em rochas peralcalinas de outras localidades não seja surpreendente.

CONCLUSÕES Em vista dos resultados discutidos, a seqüência seguinte de eventos é postulada para a geração das rochas que compõem os stocks de Serrita.

1. Fusão parcial de uma fonte granada anfibolítica gerando líquidos granodioríticos ricos em álcalis e alumina.

2. Colocação e cristalização dos magmas gerados a profundidade entre 18 e $25 \mathrm{~km}$ ( $6.8 \mathrm{kbar})$, que produzem granodioritos com afinidades trondhjemíticas.

3. Rápido soerguimento crustal que faz o magma residual perder sua fase volátil ou, caso já esteja totalmente cristalizado, que provoca refusão e formação de líquidos graníticos.

4. Subida diapírica, migração dos líquidos graníticos para os bordos da intrusão e cristalização em níveis crustais mais elevados que os granodioritos. Entre esta fase e a anterior há a colocação dos diques leucocráticos. Concomitante a esta fase, ou logo após ela, há o desenvolvimento de falhas, principalmente nos bordos dos stocks, que contribuem para realçar os granitos em relação aos granodioritos.

5. Erosão intensa que expõe as porções mais profundas da intrusão; os granitos peralcalinos ficam em relevo, em parte devido a sua maior resistência à erosão e em parte por ação de falhas.

Agradecimentos Este trabalho foi realizado com recursos do Convênio Projeto de Apoio ao Desenvolvimento Científico e Tecnológico (PADCT) - Universidade Federal de Pernambuco (UFPE). Somos gratos ao professor Dr. Alcides N. Sial por ceder dados inéditos de isótopos de oxigênio e pela revisão do manuscrito. 


\section{REFERÊNCIAS BIBLIOGRÁFICAS}

ALMEIDA, F.F.M. de; LEONARDOS, O.H.; VALENCA, J. - 1967 - Review on granitic rocks of Northeast South America In: IUGS/UNESCO SYMPOSIUM, Recife, 1967, Atas..., 41 p.

ARTH, J.G.; BARKER, F.; PETERMAN, Z.E.; FRIEDMAN, I. 1978 - Geochemistry of the gabro-diorite-tonalitetrondhjemite suite of southwest Finland and its implication for the origin of tonalitic and trondhjemitic magmas. J. Petrol., 19:289-316.

BARBOSA, O. - 1970 - Geologia econômica de parte da região do Médio São Francisco, Nordeste do Brasil. DNPM/DFPM 97 p. (Boletim 140).

BARKER, F. - 1979 - Trondhjemite: definition, environment and hypothesis of origin. In: BARKER, F. ed. Trondhjemites, dacites, and related rocks. Amsterdam, Elsevier. p. 1-12.

BARKER, F.; FRIEDMAN, I.; HUNTER, D.R.; GLEASON, J. 1976 - Oxygen isotopes of some trondhjemites, acidic gneisses, and associated mafic rocks. Precambr. Res., 3:547-57.

BOWDEN, P. \& TURNER, D.C. - 1974 - Peralkaline and associated ring-complexes in the Nigeria-Niger Province, West Africa. In: SORENSEN, H. ed. The alkaline rocks. New York, Wiley \& Sons, p. 330-354.

BOWDEN, P. \& WHITLEY, J.F. - 1974 - Rare earth patterns in peralkalic and associated granite. Lithos, 7:15-21.

CALDASSO, A.L.S. - 1967a - Geologia da quadrícula E-094, Folha Crato. Recife Sudene, Dep. Rec. Nat. 36 p. (Série Geologia Regional, 3).

CALDASSO, A.L.S. - 1967b - Geologia da quadrícula E-093, Fólha Crato. Recife Sudene, Dep. Rec. Nat. 47p. (Série Geologia Regional, 4).

CULLERS R.L.\& GRAF, J.L. - 1984 - Rare earth elements in igneous rocks of the continental crust: intermediate and silicic rocks-ore petrogenesis. In: HENDERSON, P. ed. Rare earth element geochemistry. Amsterdam, Elsivier. p. 275-316.

FERREIRA, V.P. \& SIAL, A.N. - 1985 - The peralkalic magmatism in the Precambrian Cachoeirinha-Salgueiro foldbelt, Northeast Brazil: Geochemical aspects. Rev. Bras. Geoc., 16(1).

HALL, A. - 1971 - The relationship between geothermal gradient and the composition of granitic magmas in orogenic belts. Contr. Miner. Petrol., 32:186-92.

HANSON, G.N. - 1980 - Rare earth elements in petrogenetic studies of igneous systems. Ann. Rev. Earth Planet. Sci., 8:371-406.

HARRIS, N.B.W. \& MORRINER, G.F. - $1980-$ Geochemistry and petrogenesis of a peralkaline granite complex from the Midian Mountains, Saudi Arabia. Lithos., 13:325-37.

HIBBARD, M.J. - 1979 - Myrmekite as a marker between preaqueous and postaqueous phase saturation in granitic systems. Geol. Soc. Amer. Bull., 90:1047-62.
NANEY, M.T. - 1983 - Phase equilibria of rock-forming ferromagnesian silicates in granitic systems. Am. J. Sci., 283:933-1033.

O'CONNOR, J.T. - 1965 - A classification for quartz-rich igneous rocks based on feldspar ratios. U.S. Geol. Surv. Prof. Pap., 525-B:79-84

PEARCE, J.A.; HARRIS, N.B.W.; TINDLE, A.G. - 1984 - Trace element discrimination diagrams for the tectonic interpretation of granitic rocks. J. Petrol., 25:956-83.

PITCHER, W.S. - 1979 - The nature, ascent and emplacement of granitic magmas. J. Geol. Soc., 136:627-62.

SIAL, A.N. - 1984a - Litogeoquímica de elementos terras-raras na caracterização de granitóides do Espaço Cachoeirinha, Nordeste do Brasil. In: CONGR. BRAS. GEOL., 33, Rio de Janeiro, 1984, Anais... Rio de Janeiro, SBG. p. 2697-709.

SIAL, A.N. - 1984b - Padrão regional de isótopos de oxigênio em granitóides do Espaço Cachoeirinha, Nordeste do Brasil. In: CONGR. BRAS. GEOL., 33, Rio de Janeiro, 1984, Anais... Rio de Janeiro, SBG. p. 2710-722.

SIAL, A.N.; LIMA, E.S.; PESSOA, D.A.; CASTRO, C.; VILLARROEL, H.S.; RODRIGUES DA SILVA, M.R.; BORBA, G.S.; LIMA, G.R. - 1981a - Geoquimica de dois stocks granodioriticos de Serrita (PE): elementos maiores. UFPE, Dep. Geol, Estudos Pesquisas p. 27-52 (Boletim 4).

SIAL, A.N.; PESSOA, D.A.; LIMA, E.S.; VILLARROEL, H.S.; CASTRO, C.; RODRIGUES DA SILVA, M.R.; BORBA, G.S. 1981b - Petrologia e geoquímica do batólito de Bodocó e stocks de Serrita, Pernambuco. In: SIMP. GEOL. NORDESTE, 10, Recife, 1981. Atas... Recife, SBG/Núcleo Nordeste, p. 388-401.

SIAL, A.N.; BRITO NEVES, B.B.; BEURLEN, H.; MELO, P.G.; PESSOA, R.J.R. - 1983 - Projeto Extremo Oeste de Pernambuco, Quadrículas de Salgueiro e Partes de Chorrochó e Parnamirim. Recife, Convênio DNPM/UFPE. 51 p. (Relatório Final).

SILVA FILHO, M.A. da - 1985 - Projeto Cachoeirinha, Recife, Convênio DNPM/CPRM, Vol. 1, 128 p. (Relatório Final).

TAYLOR, H.P. - 1977 - Water/rock interactions and the origin of $\mathrm{H}_{2} \mathrm{O}$ in granitic batholiths. J. Geol. Soc., 133:509-558.

ZEN, E-an - 1985 - Implications of magmatic epidote-bearing plutons on crustal evolution in the accreted terranes of northwestern North America. Geology, 13:266-69.

ZEN, E-an \& HAMMARSTROM, J.M. - 1984 - Magmatic epidote and its petrologic significance. Geology, 12:515-18.

MANUSCRITO

Recebido em 20 de fevereiro de 1986 Revisão aceita em 15 de maio de 1986 